\title{
Mechanical Properties of Concrete Using Eggshell Ash and Rice Husk Ash As Partial Replacement Of Cement
}

\author{
Nurul Shahadahtul Afizah Asman ${ }^{1,}$, Salinah Dullah ${ }^{1}$, Janice Lynn Ayog ${ }^{1}$, Adriana \\ Amaludin ${ }^{1}$, Hassanel Amaludin ${ }^{1}$, C. H. Lim ${ }^{1}$, and Aslina Baharum ${ }^{2}$ \\ ${ }^{1}$ Faculty of Engineering, Universiti Malaysia Sabah, Jalan UMS, 88400, Kota Kinabalu, Sabah, \\ Malaysia \\ ${ }^{2}$ Faculty of Computer and Informatics, University Malaysia Sabah, Jalan UMS, 88400 Kota Kinabalu, \\ Sabah, Malaysia
}

\begin{abstract}
This research was carried out to determine the optimum percentage of eggshell ash and rice husk ash (RHA) as partial cement replacement. The samples were tested for its mechanical properties by using concrete grade G30 with cube mould (100 mm x $100 \mathrm{~mm}$ x $100 \mathrm{~mm}$ ) and prisms $(100 \mathrm{~mm} \times 100 \mathrm{~mm} \times 500 \mathrm{~mm})$. The samples were mixed with eggshell ash and RHA admixture with different proportions (2\%:8\%, $4 \%: 6 \%, 6 \%: 4 \%$ ). Several types of test were conducted towards the samples, which are the slump test, compressive and flexural test. Based on previous researches, the strength of concrete reduced as replaced with eggshells. Most of the researches show the similar trend when partial cement is replaced using eggshell ash. Thus, to increase the strength, an admixture which has pozzolanic reactivity called rice husk ash (RHA) is introduced into mix design which has been proved can help to improve the strength of concrete.
\end{abstract}

\section{Introduction}

Concrete is commonly utilized as a material to construct building structures such as beam, column and slab due to its sustainability of carrying large loads. Nevertheless, concrete strength has its limit when it comes to excessive force exerted that may lead to concrete failure. In order to overcome the problem, identification of various researches on discovery of new materials has been made. This research addresses the effects on the strength of concrete by using eggshells as partial cement replacement with proper proportion in concrete mix.

Thereunto, a growing concern worldwide of reducing and reusing waste materials as resources for producing renewable material which have the possibility to be counted on as an alternative or substitute to the existing material has become awareness. This may assist in providing cooperation to any parties involved in reducing the amount of waste as well as to protect the environment. Also, increasing demand for cement in recent days has led to a

* Corresponding author: nurulshahadahtul@gmail.com 
boost production of cement in the world. The increase amount was predicted from 2283 million tones in 2005 to about 2836 million tones in the year of 2010 due to emerging economics and developing countries particularly in Asia countries with nearly produced $70 \%$ of the world production. The objectives of conducting this research are to determine the optimum percentage of eggshell ash and rice husk ash (RHA) as partial cement replacement. Also, determine the mechanical properties of concrete by comparing the performance of the concrete with the conventional concrete. The scope of this research is limited to partial replacement of cement using recycle wastes such as eggshell and rice husk ash.

\section{Effects of eggshell ash and rice husk ash (RHA)}

According to Okonkwo et al. [1], eggshell is mainly composed of calcium compounds that is very similar to that of cement and presented as being composed of $93.70 \%$ calcium carbonate. Thus, it is an alternative that enables the cement to be replaced with eggshell. It is an advantage where the amount of cement usage can be reduced at the same time saves budget for any project. Calcium oxide is produced when calcium carbonate is incinerated to ash at temperature $500^{\circ} \mathrm{C}$ and provides as a good accelerator due to extra calcium oxide in it. Calcium oxide also improved the setting time, as minimizing the length of setting time is much desirable in construction industry since it can be interrupted by unpredictable weather especially in the rainy season. Several researches conducted before also discovered the similar trend reduction in strength. For example, cement replacement by using timber waste ash and potential of wood waste ash as an addictive in concrete [2-3]. Assessments made by these researchers, were focused on mechanical strength, durability and shrinkage properties. However, the results indicated that as the number of percentage of cement being replaced, compressive strength of mortar decreased. Not only that, a remarkable decrease of air permeability was observed.

Most of researches state similar reduction in strength of concrete, another material has to be added together into the mix that has give positive impacts to concrete. Jayasankar [4] stated that the combination of fly ash, rice husk ash and eggshell powder was confirmed has equal strength with the conventional concrete. Thus, rich husk ash is chosen as an admixture to be added into the mix at the same time without changing the eggshell ash as partial cement replacement.

Rice Husk Ash (RHA) helps to improve the pozzolanic reactivity of cement. This pozzolanic reactivity refers to the high content of amorphous silica and to a very large surface area governed by the porous structures of the particles. The fineness of the RHA also assists in the reactivity by providing a larger surface area for a better reaction.

Researchers Cheah and Ramli [5] also stated that the improvement in the compressive strength and flexural strength of cement mortar with the use of high calcium wood ash (HCWA) in combination with densified silica fume (DSF) is due to the higher rate of pozzolanic reaction between the amorphous silica mineral of DSF and Portland cement contributed by HCWA. It is similar when eggshell ash, which consists of mainly of calcium to be reacted with RHA that content of pozzolanic amorphous silica.

According to Chao-Lung et al. [6], by adding the ground RHA up to $20 \%$, concrete can be strengthen and enhance the durability properties of concrete. It improved the compressive strength, resistance to electricity and ultrasonic pulse velocity. Furthermore, as the number of curing day increases, higher strength and resistivity are gained.

Meanwhile, according to research done by Sensale [7] stated that by replacing Portland cement by RHA proven to enhance the performance of the concrete. The physical effect is linked to particle size that produces a refinement on the pore structure. But the degree of fineness of RHA has certain level that is allowable to be achieved. During the grinding of 
RHA, high degree of fineness should be avoided. This is because the derivation of pozzolanic activity is mainly come from the internal surface area of the particles. It is suggested that at least about $75 \%$ of the RHA particles are in a size range at from about 4 $\mu \mathrm{m}$ to about $75 \mu \mathrm{m}[7]$.

These show that there is a linear relationship as the percentage of RHA added into concrete mix increases, so does the compressive strength compared to conventional concrete. Simultaneously, a durability study of high strength of concrete mixed with part replacement of cement by RHA should be conducted along with its economic aspects.

\section{Methodology}

Laboratory experiments were conducted by using main ingredients of concrete mix design, cement, fine aggregate, coarse aggregate and water. Meanwhile, eggshell ash and RHA were used as partial substitutes for cement in the mix design. After that, tests were conducted such as slump, compressive strength and flexural strength tests. Then the data for all experiments were recorded for the analysis.

Eggshells were collected from restaurants near the school and incinerated into ash with temperature about $500^{\circ} \mathrm{C}$, thoroughly ground and sieved through $75 \mu \mathrm{m}$ sieve. In the meantime, RHA was obtained from a factory that was already burnt through combustion process.

The mix design is based on grade G30 (1:2:3). The $100 \mathrm{~mm} \times 100 \mathrm{~mm} \times 100 \mathrm{~mm}$ cubes and $100 \mathrm{~mm} \times 100 \mathrm{~mm} \times 500 \mathrm{~mm}$ prisms were used to observe the strength at 7, 21 and 28 days of curing.

The test specimens were mixed with eggshell ash and RHA admixture added. Partial cement will be replaced using eggshell ash with RHA during mixing the concrete design according to determined proportions. Table 1 shows the proportions of cement that is partially mixed with eggshell ash and RHA for each test.

Laboratory experiments were conducted by using main ingredients of concrete mix design, cement, fine aggregate, coarse aggregate and water. Meanwhile, eggshell ash and RHA were used as partial substitutes for cement in the mix design. After that, tests were conducted such as slump, compressive strength and flexural strength tests. Following that, the data for all experiments were recorded for the analysis.

Eggshells were collected from restaurants near the school and incinerated into ash with temperature about $500^{\circ} \mathrm{C}$, thoroughly ground and sieved through $75 \mu \mathrm{m}$ sieve. In the meantime, RHA was obtained from a factory that was already burnt through combustion process.

The mix design is based on grade G30 (1:2:3). The $100 \mathrm{~mm} \times 100 \mathrm{~mm} \times 100 \mathrm{~mm}$ cubes and $100 \mathrm{~mm} \times 100 \mathrm{~mm} \times 500 \mathrm{~mm}$ prisms were used to observe the strength at 7, 21 and 28 days of curing.

The test specimens were mixed with eggshell ash and RHA admixture added. Partial cement will be replaced using eggshell ash with RHA during mixing the concrete design according to determined proportions. Table 1 shows the proportions of cement that is partially mixed with eggshell ash and RHA for each test.

Table 1. Proportions of cement, eggshell ash and RHA.

\begin{tabular}{|c|c|c|c|}
\hline & Cement & Eggshell ash & RHA \\
\hline Normal concrete G30 & $100 \%$ & - & - \\
\hline Concrete A & $90 \%$ & $2 \%$ & $8 \%$ \\
\hline Concrete B & $90 \%$ & $4 \%$ & $6 \%$ \\
\hline Concrete C & $90 \%$ & $6 \%$ & $4 \%$ \\
\hline
\end{tabular}




\section{Results}

\subsection{Slump test}

Based on ASTM C 143, concretes with replacement eggshell and RHA is more workable compared to normal concrete G30, as shown in Fig. 1. Normal concrete G30 and concrete with $2 \%$ eggshell ash and $8 \%$ RHA are considered less workable and have high tendency to segregate. Concrete with $4 \%$ eggshell height of slump continues to increase as shown by concrete with 6\% eggshell ash and 4\% RHA replaced with 6\% RHA is considered workable in this result.

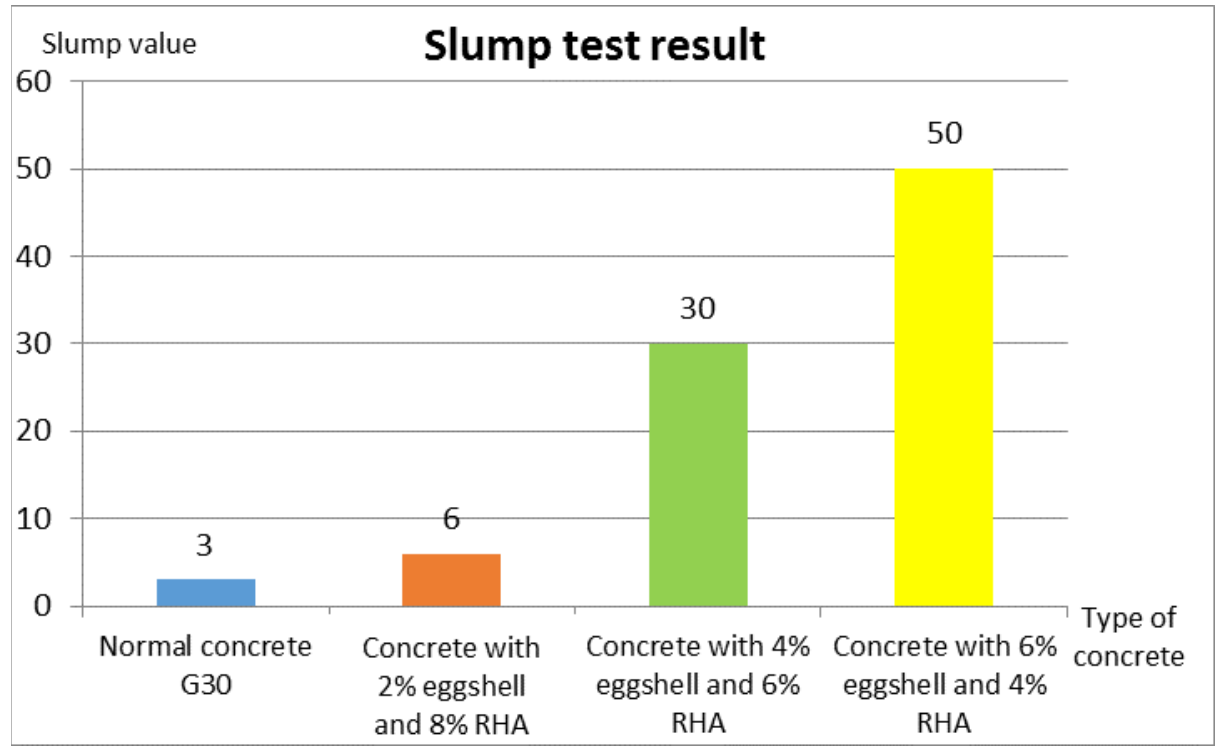

Fig. 1. Workability of Normal Concrete G30, Concrete with Addition of Eggshell and RHA.

\subsection{Compressive strength}

For compressive strength, replacement of eggshell ash and RHA reduced the strength. Nevertheless, strength of concrete is developed at 28 days of curing. In addition, as the percentage of replacement eggshell ash increased along with reduction in percentage of RHA. The result for flexural strength also almost shows a proportional performance same as compressive strength as shown in Fig. 2. However, for concrete with $6 \%$ eggshell ash and $4 \%$ RHA the flexural strength reduced.

\subsection{Flexural strength}

Based on the result it can be considered that concrete with replacement of $4 \%$ eggshell ash and $6 \%$ RHA is the best optimum usage with a targeted slump between $10 \mathrm{~mm}$ to $30 \mathrm{~mm}$ and improved strength development in flexural between 7 to 28 days of curing although its compressive strength is lower that concrete with $6 \%$ eggshell ash and 4\% RHA (Fig. 3). 


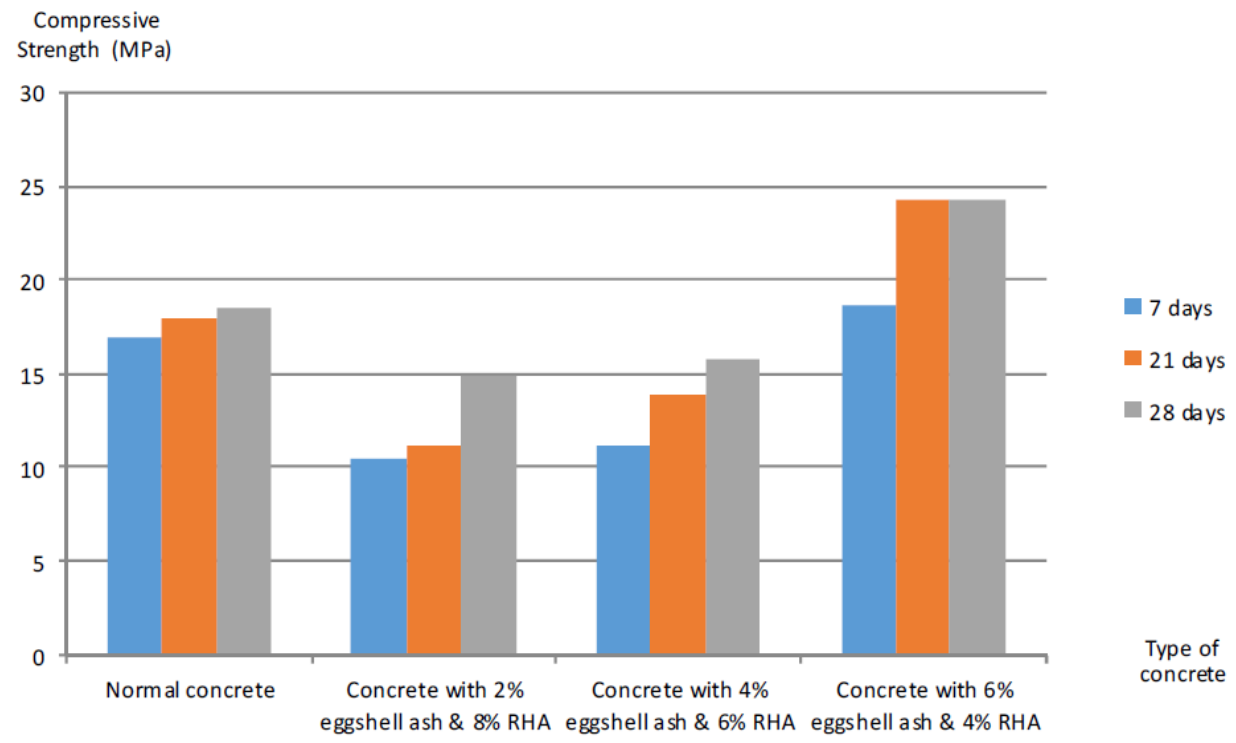

Fig. 2. Compressive strength of normal concrete G30, concrete with addition of eggshell and RHA.

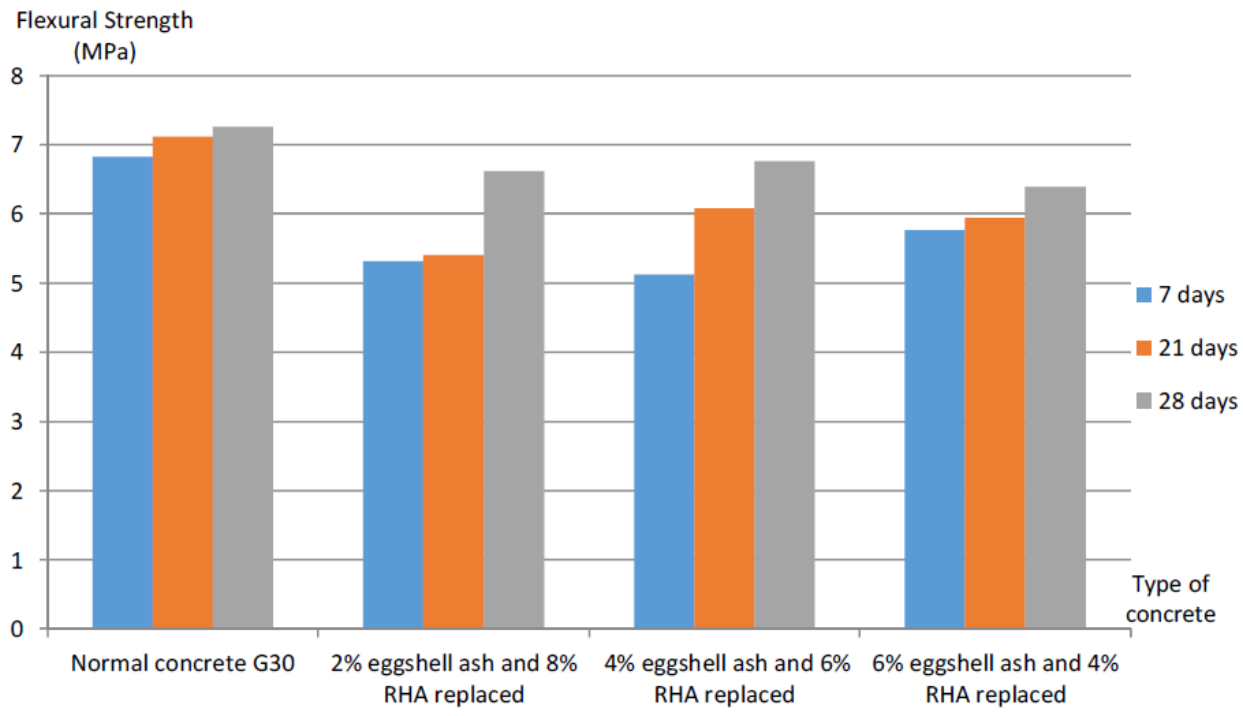

Fig. 3. Flexural strength of normal concrete G30 and concrete with addition of eggshell ash and RHA.

\subsection{Comparison with conventional concrete}

When it comes to comparing the obtained results between conventional uses based on workability, the concrete with $2 \%$ eggshell ash and $8 \%$ RHA can be used for road. Meanwhile, concrete with 4\% eggshell ash and 6\% RHA is suitable for road and light reinforcement. Other than that, $6 \%$ eggshell ash and 4\% RHA can be applied for flat slab and heavy reinforcement. 


\section{Conclusion}

This research results shows workability in slump test can only be achieved with the mixing of $4 \%$ eggshell ash and 6\% RHA with is reaching to $30 \mathrm{~mm}$ slump. Meanwhile, for the normal concrete G30 and concrete with 2\% eggshell ash and 8\% RHA are less workable with $3 \mathrm{~mm}$ and $6 \mathrm{~mm}$ slump respectively. Concrete with $2 \%$ eggshell and $8 \%$ RHA is classified as very low degree of workability with $6 \mathrm{~mm}$ slump and can be applied for making road. Meanwhile, Concrete with 4\% eggshell ash and 6\% RHA is classified as low degree of workability with $30 \mathrm{~mm}$ slump and can be applied for making road and light reinforcement of concrete. Lastly, concrete with 6\% eggshell ash and 4\% RHA is classified as medium degree of workability with $50 \mathrm{~mm}$ slump and can be applied for making road and heavy reinforcement of concrete.

Overall, for compressive and flexural strength of the concrete with eggshell ash and RHA replaced gains lower strength compared to normal concrete using fully OPC. However, the strength developed from day 7 to day 28 due to pozzolanic effect that refers to high content of amorphous silica that gives positive effect to the strength of concrete.

The authors of this paper would like to express their gratitude and sincere appreciation to University Malaysia Sabah for providing the financial support.

\section{References}

[1] U.N. Okonkwo, I.C. Odiong, and E.E. Akpabio, The effects of eggshell ash on strength properties of cement-stabilized lateric, Int. J. of Sustainable Construction Engineering and Technology, 13(1),18-25 (2012)

[2] A.U. Elinwha and Y.A. Mohmood, Ash from timber waste as cement replacement material, 24(2), 219-222 (2012)

[3] F. Udoeyo, H. Inyang, D. Young, and E. Oparadu, Potential of wood waste ash as an additive in concrete, J. Mater. Civ. Eng., 18(4), 605-611 (2006)

[4] R. Jayasankar, N. Mahindran, and R. Ilangovan, Studies on concrete using fly ash, rice husk ash and egg shell powder, Int. J. of Civil and Structural Engineering, Integrated Publishing Services, 1(3), 362-372, (2010)

[5] C.B. Cheah and M. Ramli., Mechanical strength, durability and drying shrinkage of structural mortar containing HCWA as partial replacement of cement, Construction and Building Materials, 30, 320-329 (2011)

[6] H.C. Lung, B.L. Tuan, and C.C. Tsun, Effect of rice husk ash on the strength and durability characteristics of concrete, Construction and Building Materials, 25, 37683772 (2011)

[7] G.R. de Sensale, Effect of rice husk ash on durability of cementitious materials, Cement and Concrete Research, 32,718-725 (2010) 